\title{
Human ALKBH7 is required for alkylation and oxidation-induced programmed necrosis
}

\author{
Dragony Fu, Jennifer J. Jordan, and Leona D. Samson ${ }^{1}$ \\ Department of Biological Engineering, Department of Biology, Center for Environmental Health Sciences, David H. Koch Center \\ for Integrative Cancer Research, Massachusetts Institute of Technology, Cambridge, Massachusetts 02139, USA
}

Programmed necrosis has emerged as a crucial modulator of cell death in response to several forms of cellular stress. In one form of programmed necrotic cell death, induced by cytotoxic alkylating agents, hyperactivation of poly-ADP-ribose polymerase (PARP) leads to cellular NAD and ATP depletion, mitochondrial dysfunction, reactive oxygen species formation, and ensuing cell death. Here, we show that the protein encoded by the human AlkB homolog 7 (ALKBH7) gene plays a pivotal role in DNA-damaging agent-induced programmed necrosis by triggering the collapse of mitochondrial membrane potential and large-scale loss of mitochondrial function that lead to energy depletion and cellular demise. Depletion of ALKBH7 suppresses necrotic cell death induced by numerous alkylating and oxidizing agents while having no effect on apoptotic cell death. Like wild-type cells, ALKBH7-depleted cells undergo PARP hyperactivation and NAD depletion after severe DNA damage but, unlike wild-type cells, exhibit rapid recovery of intracellular NAD and ATP levels. Consistent with the recovery of cellular bioenergetics, ALKBH7-depleted cells maintain their mitochondrial membrane potential, plasma membrane integrity, and viability. Our results uncover a novel role for a mammalian AlkB homolog in programmed necrosis, presenting a new target for therapeutic intervention in cancer cells that are resistant to apoptotic cell death.

[Keywords: AlkB; ALKBH7; death; DNA damage; necrosis]

Supplemental material is available for this article.

Received February 8, 2013; revised version accepted April 10, 2013.

Programmed cell death can occur by a number of mechanisms that include classical apoptosis plus several recently described nonapoptotic pathways, such as lysosomal-mediated cell death, cell death with autophagy, and programmed necrosis (for review, see Kroemer and Jaattela 2005; Vandenabeele et al. 2010; Green et al. 2011; Vanlangenakker et al. 2012). One type of programmed necrosis, termed necroptosis, has emerged as a critical factor associated with a variety of pathological processes, including acute pancreatitis, inflammation, excitotoxicity, and cardiac cell death during ischemia-reperfusion (for review, see Vanlangenakker et al. 2012). In addition, necrosis is critical for an optimal immune response to bacterial and viral pathogens (for review, see Mocarski et al. 2012), underscoring the crucial role for programmed necrosis in maintaining organismal health.

Programmed necrosis can be induced by extensive DNA damage caused by oxidizing agents or cancer chemothera-

\footnotetext{
${ }^{1}$ Corresponding author

E-mail lsamson@mit.edu

Article published online ahead of print. Article and publication date are online at http://www.genesdev.org/cgi/doi/10.1101/gad.215533.113.
}

peutic drugs such as alkylating agents (Yu et al. 2002; Du et al. 2003; Zong et al. 2004; Zong and Thompson 2006; Moubarak et al. 2007; Oka et al. 2008). DNA damageinduced necrosis is characterized by the hyperactivation of $\mathrm{NAD}^{+}$-dependent poly-ADP-ribose polymerase (PARP), which leads to intracellular $\mathrm{NAD}^{+}$depletion, loss of ATP production, mitochondria depolarization, generation of reactive oxygen species (ROS), and eventual loss of total cellular bioenergetics (Ha and Snyder 1999; Cipriani et al. 2005; Alano et al. 2010; Tang et al. 2010; Goellner et al. 2011; Luo and Kraus 2012). In addition to mitochondrial dysfunction, severe DNA damage can induce the translocation of the apoptosis-inducing factor (AIF) from the mitochondria to the nucleus, where AIF forms a DNAdegrading complex with histone $\mathrm{H} 2 \mathrm{AX}$ and cyclophilin D (Yu et al. 2002; Baritaud et al. 2010). This cascade of events contributes to the ultimate demise of the cell, characterized by cell swelling, large-scale chromosome fragmentation, and eventual plasma membrane disintegration (Vandenabeele et al. 2010).

Cells possess numerous mechanisms to repair DNA damage and counteract the cytotoxic and mutagenic effects of DNA damage. One of the most recently discovered re- 
pair mechanisms for alkylated DNA bases is direct DNA damage reversal catalyzed by the bacterial AlkB dioxygenase (for review, see Sedgwick et al. 2007; Yi and He 2013). The Escherichia coli AlkB protein has been characterized as a DNA repair enzyme that catalyzes oxidative demethylation of the cytotoxic alkyl DNA base lesions 1-methyladenine (1meA) and 3-methylcytosine (3meC) (Falnes et al. 2002; Trewick et al. 2002). The mammalian genome encodes nine AlkB homologs (ALKBH1 through ALKBH8 plus the FTO gene product). Of the nine ALKBH proteins, ALKBH1, ALKBH2, ALKBH3, and FTO display DNA repair activity on methylated DNA substrates in vitro (Duncan et al. 2002; Aas et al. 2003; Gerken et al. 2007; Jia et al. 2008; Westbye et al. 2008). Mouse knockout studies have shown that $\mathrm{ALKBH} 2$ is the major repair protein for 1meA in DNA (Ringvoll et al. 2006), while ALKBH3 has been shown to play a role in the repair of $3 \mathrm{meC}$ lesions in human cells (Dango et al. 2011).

Besides the repair of alkylated DNA base substrates, bacterial AlkB, ALKBH1, ALKBH2, ALKBH3, and FTO can repair methylated RNA bases in vitro and potentially in vivo using the same oxidative demethylation reaction as for DNA (Aas et al. 2003; Ougland et al. 2004; Lee et al. 2005; Jia et al. 2008; Westbye et al. 2008; Vagbo et al. 2013). Moreover, mammalian ALKBH8 has been shown to modify specific tRNAs, which in turn modulate the DNA damage response and enhance survival (Fu et al. 2010; Songe-Moller et al. 2010), thus expanding the role of mammalian ALKBH enzymes beyond nucleic acid repair to include RNA modification. Even more recently, ALKBH5 has been shown to catalyze the demethylation of $\mathrm{N}(6)$-methyladenosine in mRNA to affect mRNA export and RNA metabolism (Zheng et al. 2013). The large number of AlkB homologs in mammalian cells, combined with their emerging functions in diverse cellular processes, suggests additional biological roles for the remaining ALKBH proteins.

Here, we show that one of the human AlkB homologs, $\mathrm{ALKBH} 7$, is a mitochondrial protein required for programmed cell necrosis induced by alkylating agents or oxidative stress. Loss of ALKBH7 suppresses such necrosis and prevents the loss of mitochondrial function and cellular bioenergetics induced by DNA-damaging agents that lead to necrotic cell death. The findings in this study identify a novel cellular role for an ALKBH dioxygenase protein in the execution of programmed necrotic cell death induced by genotoxic stress.

\section{Results}

ALKBH7 is a nuclear-encoded protein that is imported into mitochondria

Previous studies by our laboratory and others have shown that mammalian ALKBH proteins localize to different subcellular compartments; namely, the nucleus, cytoplasm, and mitochondria (Aas et al. 2003; Tsujikawa et al. 2007; Westbye et al. 2008; Fu et al. 2010; Thalhammer et al. 2011). Based on multiple subcellular localization prediction algorithms, it appears that ALKBH7 contains a mitochon- drial targeting sequence (MTS) at the $\mathrm{N}$ terminus (Fig. 1A). Through protein tagging with a C-terminal green fluorescent protein (GFP), we found that ALKBH7 exhibits a punctate-like pattern of localization that does indeed coincide with mitochondria (Fig. 1B). In addition, we found that transiently expressed ALKBH7 fractionates into two distinct pools consisting of a larger isoform found in the cytoplasm and a faster-migrating species found only in purified mitochondria (Fig. 1C). The presence of a truncated form of ALKBH7 in the mitochondria is most likely due to processing of the $\mathrm{N}$-terminal mitochondrial localization signal after import from the cytoplasm, a common feature of many nuclear-encoded proteins that exhibit mitochondrial localization. The localization of human ALKBH7 in mitochondria is consistent with the mitochondrial localization of endogenous mouse ALKBH7 (Solberg et al. 2013). Finally, comprehensive proteomic analysis from two independent studies has detected endogenous ALKBH7 in the purified mitochondria of both human and mouse tissues (Pagliarini et al. 2008; Rhee et al. 2013). These criteria establish ALKBH7 as a nuclear-encoded protein that is translated in the cytoplasm and imported into mitochondria, suggesting that ALKBH7 plays a biological role in the mitochondria.

In addition to ALKBH7, another human AlkB homolog protein, ALKBH1, has been shown to be located in the mitochondria even though it lacks a detectable mitochondrial localization signal (Westbye et al. 2008). ALKBH1 catalyzes the direct repair of $3 \mathrm{meC}$ lesions in ssDNA in vitro (Westbye et al. 2008), suggesting that mitochondrial AlkB enzymes play a role in mitochondrial DNA repair. However, we found that purified human ALKBH7 lacked dioxygenase-mediated repair activity for both $1 \mathrm{meA}$ and $3 \mathrm{meC}$ lesions in either ssDNA or dsDNA oligonucleotides (Supplemental Fig. S1). The lack of oxidative demethylation activity exhibited by human ALKBH7 has also been observed with the mouse Alkbh7 protein (Lee et al. 2005). While ALKBH7 did not display DNA demethylase activity, we detected robust DNA repair activity for the ALKBH2 and ALKBH3 enzymes on both 1meA and $3 \mathrm{meC}$ DNA adducts (Supplemental Fig. S1), as previously described (Aas et al. 2003; Lee et al. 2005). Our studies indicate that ALKBH7 could play a unique cellular role in mitochondria distinct from known ALKBH functions in nucleic acid repair.

\section{Depletion of ALKBH7 confers resistance rather than sensitivity to DNA-damaging agents}

We showed previously that the mammalian AlkB homolog ALKBH8 confers cellular resistance to DNA-damaging agents by catalyzing tRNA modification, which in turn modulates the DNA damage response (Fu et al. 2010). Thus, AlkB homologs can influence cellular sensitivity to DNA damage through mechanisms other than direct DNA repair. To determine whether ALKBH7 plays a role in modulating sensitivity to DNA-damaging agents, we generated 293T human embryonic kidney fibroblast cell lines that were stably depleted of the ALKBH7 protein using lentiviral shRNA expression constructs targeting 
A

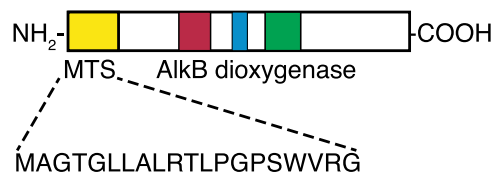

B

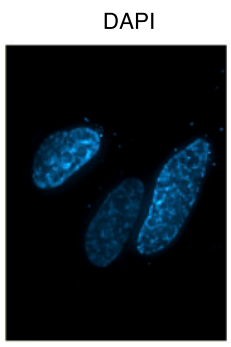

ALKBH7

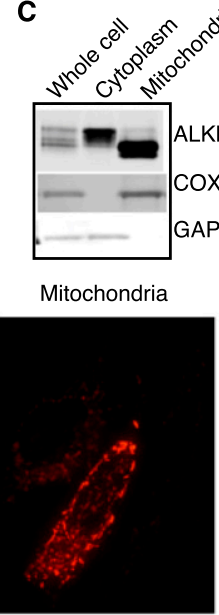

Figure 1. ALKBH7 is targeted to mitochondria. $(A)$ ALKBH7 contains a MTS at the N terminus, as predicted through primary amino acid sequence analysis and subcellular localization prediction. $(B)$ Transiently expressed ALKBH7-GFP colocalizes with mitochondria in HeLa human cervical carcinoma cells. $(C)$ ALKBH7 fractionates into a higher-molecular-weight species in the cytoplasm and a lower-molecular-weight form in purified mitochondrial fractions, indicative of mitochondrial import and processing of ALKBH7. different regions of the $A L K B H 7$ mRNA transcript (Fig. 2A). To our surprise, we found that ALKBH7-depleted cell lines became resistant to cell death induced by the alkylating agent methyl methanesulfonate (MMS) (Fig. $2 B, C)$. Cell death was significantly reduced in ALKBH7depleted cells even at doses of MMS that reduced viability to $\sim 20 \%$ in control $293 \mathrm{~T}$ cells. Transient knockdown of ALKBH7 in $293 \mathrm{~T}$ cells using siRNAs also conferred resistance to alkylating agents, recapitulating the results using stable shRNA vectors (Fig. 2D).
To confirm that ALKBH7 is indeed required for cell death in response to MMS, we tested whether re-expression of ALKBH7 in an ALKBH7-depleted cell line could suppress the MMS-resistant phenotype exhibited by ALKBH7-depleted cells. We transiently transfected either an empty vector plasmid or an ALKBH7-expressing construct into the control-sh or ALKBH7-sh cell lines, followed by treatment with MMS (Fig. 2E). As expected, control shRNA cell lines transfected with the empty vector remained sensitive to MMS, while the ALKBH7-depleted
A

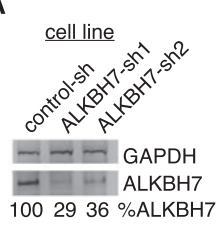

B

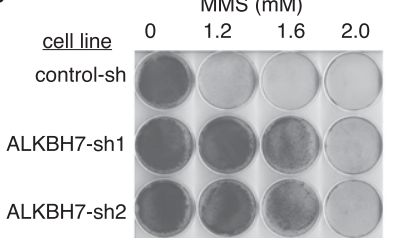

D
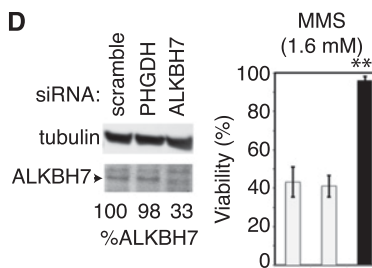

E

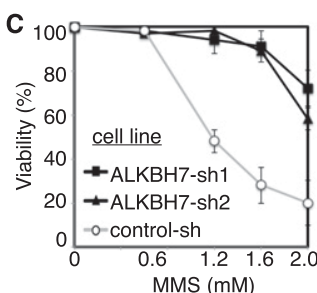

MMS (1.8 mM)

cell line: $\square$ control-sh $\square$ ALKBH7-sh1

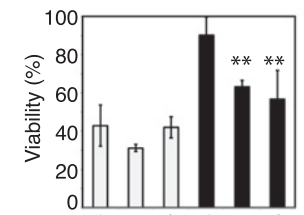

ALKBH7 plasmid:

$\mathbf{F}$

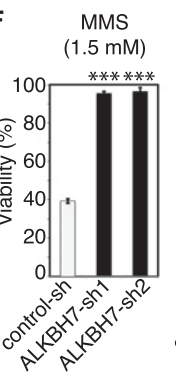

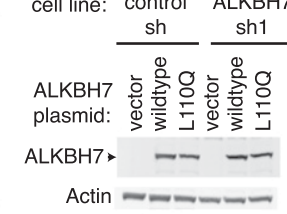

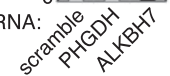

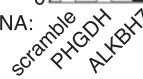

\begin{abstract}
MNNG
\end{abstract} $(50 \mu \mathrm{M})$

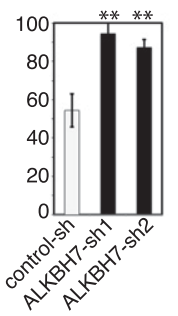

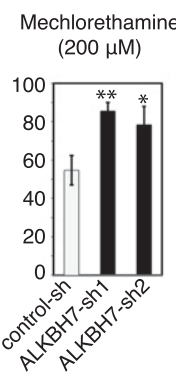

Temozolomide

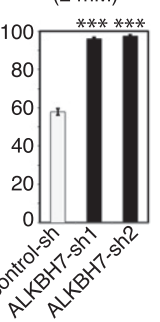

\section{$\mathrm{H}_{2} \mathrm{O}_{2}$
$(1 \mathrm{mM})$}

(1 $\mathrm{mM})$

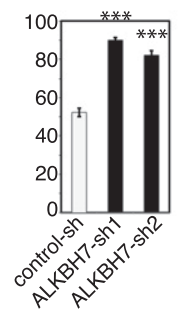

t-buOOH

$(1.5 \mathrm{mM})$

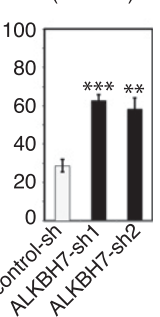

Figure 2. Depletion of ALKBH7 in 293T human embryonic kidney cells confers resistance to alkylating and oxidizing agents. $(A)$ Immunoblot analysis of ALKBH7 levels in 293T cells expressing a nonsilencing shRNA (control-sh) or either of two shRNAs targeting different regions of the ALKBH7 mRNA transcript (ALKBH7-sh1 and ALKBH7-sh2). The amount of ALKBH7 remaining in each cell type (\%ALKBH7) is expressed relative to the control-sh cell line after normalization to the levels of GAPDH. $(B)$ Representative growth of control-sh versus ALKBH7depleted 293T cell lines after treatment with the indicated amount of MMS. (C) Viability of control-sh and ALKBH7-depleted 293T cell lines after treatment with the indicated concentration of MMS, as measured by trypan blue dye exclusion. (D) Immunoblot analysis and post-MMS viability of 293T cells transfected with nonsilencing siRNA (scramble) or pooled siRNAs targeting a non-ALKBH protein-coding transcript (PHGDH) or ALKBH7 mRNA. (E) Confirmation of ALKBH7 expression in $293 \mathrm{~T}$ cell lines transfected with plasmids expressing the indicated ALKBH7 protein and viability of the transfected cells after treatment with MMS. $(F)$ Viability of control-sh and ALKBH7-depleted cell lines after exposure to the indicated alkylating or oxidizing agent. Cells were treated with MMS, MNNG, $\mathrm{H}_{2} \mathrm{O}_{2}$, and $t$-buOOH at the indicated concentration for $1 \mathrm{~h}$ in serum-free medium, while mechlorethamine and temozolomide were left in culture medium until analysis. Error bars represent the standard deviation of at least three independent experiments $(C, D, F)$ or three technical replicates $(E) .\left(^{\star}\right) P<0.05{\left({ }^{\star \star \star}\right)}_{;}\left(^{\star \star}\right) P<0.01 ; P<0.001$. 
cell line transfected with the empty vector remained resistant (Fig. 2E). In contrast, transfection of the ALKBH7 expression construct into ALKBH7-depleted cells significantly decreased their resistance to MMS (Fig. 2E). Due to incomplete transfection, not all cells were transfected with the ALKBH7 plasmid; hence, sensitivity to MMS was increased but not completely restored to the level of the control-sh cell line. Interestingly, expression of an ALKBH7 protein containing a mutation in the putative 2-oxoglutarate-binding site (L110Q) could also partially suppress MMS resistance in ALKBH7-depleted cells, suggesting that 2-oxoglutarate binding is dispensable for the prodeath function of ALKBH7.

To determine whether the resistant phenotype of ALKBH7-depleted cells was specific to MMS, we tested other alkylating agents that differ from MMS in their chemical reactivity; these include $N$-methyl- $N^{\prime}$-nitro$N$-nitrosoguanidine (MNNG) and the cancer chemotherapeutic alkylating drugs mechlorethamine (nitrogen mustard) and temozolomide. Importantly, MNNG, mechlorethamine, and temozolomide induce a different spectrum of DNA alkyl base lesions than MMS, since MNNG, mechlorethamine, and temozolomide are $S_{N} 1$ alkylating agents, while MMS is an $S_{N} 2$ alkylating agent. We found that ALKBH7depleted cell lines were resistant to cell death induced by all three compounds (Fig. 2F), indicating that ALKBH7 plays a role in the induction of cell death in response to different types of cytotoxic alkylating agents.

In addition to alkylating agents, we tested the same cell lines for their sensitivity to the oxidizing agents hydrogen peroxide $\left(\mathrm{H}_{2} \mathrm{O}_{2}\right)$ and tert-butyl-hydroperoxide ( $t$ - $\left.\mathrm{BuOOH}\right)$. Notably, we found that ALKBH7 depletion conferred significant resistance to both $\mathrm{H}_{2} \mathrm{O}_{2}$ and $t$ - $\mathrm{BuOOH}$ (Fig. $2 \mathrm{~F})$, indicating that ALKBH7 is involved in both alkylation and oxidation-induced cell death. Importantly, the resistance phenotype associated with ALKBH7 depletion was not limited to $293 \mathrm{~T}$ human cells since knockdown of ALKBH7 in HeLa cervical carcinoma cells also confers resistance to either MMS or $t-\mathrm{BuOOH}$ (Supplemental Fig. S2). To our knowledge, this is the first ALKBH protein for which cellular depletion leads to resistance to cytotoxic damaging agents.

\section{ALKBH7 is required for necrosis induced by DNA-damaging agents}

The fact that ALKBH7 depletion confers resistance to alkylating and oxidizing agents suggests that ALKBH7 may play a novel role in promoting cell death in response to DNA damage. To explore the biological role of ALKBH7, we examined DNA damage stress signaling pathways in control and ALKBH7-depleted cells upon MMS exposure. Both control and ALKBH7-depleted cells displayed normal activation of canonical DNA damage stress signaling proteins, including phosphorylation of p53 and Chk1 (Supplemental Fig. S3A). These results suggest that ALKBH7-depleted cells undergo DNA damage to the same extent as the parental cells and that they elicit a normal DNA damage signaling response, at least initially.
Previous studies have shown that severe DNA damage caused by alkylating or oxidizing agents can trigger a caspase-independent programmed necrotic cell death pathway that displays cellular and molecular features distinct from apoptotic cell death (Zong and Thompson 2006; Eisenberg-Lerner and Kimchi 2007; Trivedi et al. 2008). Moreover, a recent study has shown that 293T cells undergo necrosis after treatment with MNNG alkylating agent (Ethier et al. 2012). Indeed, we observed the typical hallmarks of necrotic cell death in 293T cells treated with either MMS or $\mathrm{H}_{2} \mathrm{O}_{2}$, including increased cell volume, translucent cytoplasm, aggregation of intact nuclei, and plasma membrane disintegration (Fig. 3A). The loss of plasma membrane integrity in MMS-treated cells was confirmed by 7-aminoactinomycin D (7AAD) staining of nuclear DNA, which revealed cell permeabilization starting at $6 \mathrm{~h}$ post-MMS treatment, leading to complete loss of cell integrity at $24 \mathrm{~h}$ (Fig. 3B). The initial loss of viability and plasma membrane integrity in MMS-treated cells occurred in the absence of typical apoptotic markers such as decreased cell volume, membrane blebbing, early phosphatidylserine exposure, caspase activation, or PARP cleavage (Fig. 3A-D). We thus infer that 293T cells undergo necrosis rather than apoptosis after exposure to MMS. In contrast to control cells, ALKBH7-depleted cells remained adherent to the plate and maintained plasma membrane integrity even at doses of alkylating agents that induce severe DNA damage, consistent with the maintenance of cell viability and resistance to alkylation-induced cell death (Fig. 3A,B).

Since ALKBH7 depletion can prevent necrotic cell death, we tested whether ALKBH7 could also protect against apoptosis. We treated control and ALKBH7-depleted cell lines with DNA-damaging agents known to induce apoptosis in 293T cells; namely, UV and etoposide (Mourtada-Maarabouni et al. 2009; Zalckvar et al. 2010). In addition, we tested staurosporine (STS), a well-characterized inducer of apoptosis. In contrast to being resistant to alkylation- and oxidation-induced necrosis, ALKBH7depleted cell lines underwent levels of apoptosis similar to those of control cells after treatment with either UV, etoposide, or STS, as judged by caspase activation, PARP cleavage, and eventual cell death (Fig. 3C-E). In addition, we found that transient expression of the apoptosisinducing protein BAX induced apoptosis and cell death in control and ALKBH7-depleted cells to a similar extent (Fig. 3F). Finally, while the pan-caspase inhibitor z-vadfmk abrogated BAX-induced apoptotic cell death, there was no effect of $z$-vad-fmk on cell death induced by MMS (Fig. 3G), further indicating that alkylating agents induce a necrotic cell death pathway in $293 \mathrm{~T}$ cells. Taken together, our results show that ALKBH7 depletion specifically protects against necrotic cell death without affecting apoptotic cell death pathways.

Recent studies have shown that the RIP kinases play a role in programmed necroptosis induced by death receptors and some forms of DNA damage (Biton and Ashkenazi 2011; Feoktistova et al. 2011; Tenev et al. 2011; Yang et al. 2011). However, programmed necrotic cell death induced by either alkylating or oxidizing agents has been shown to 

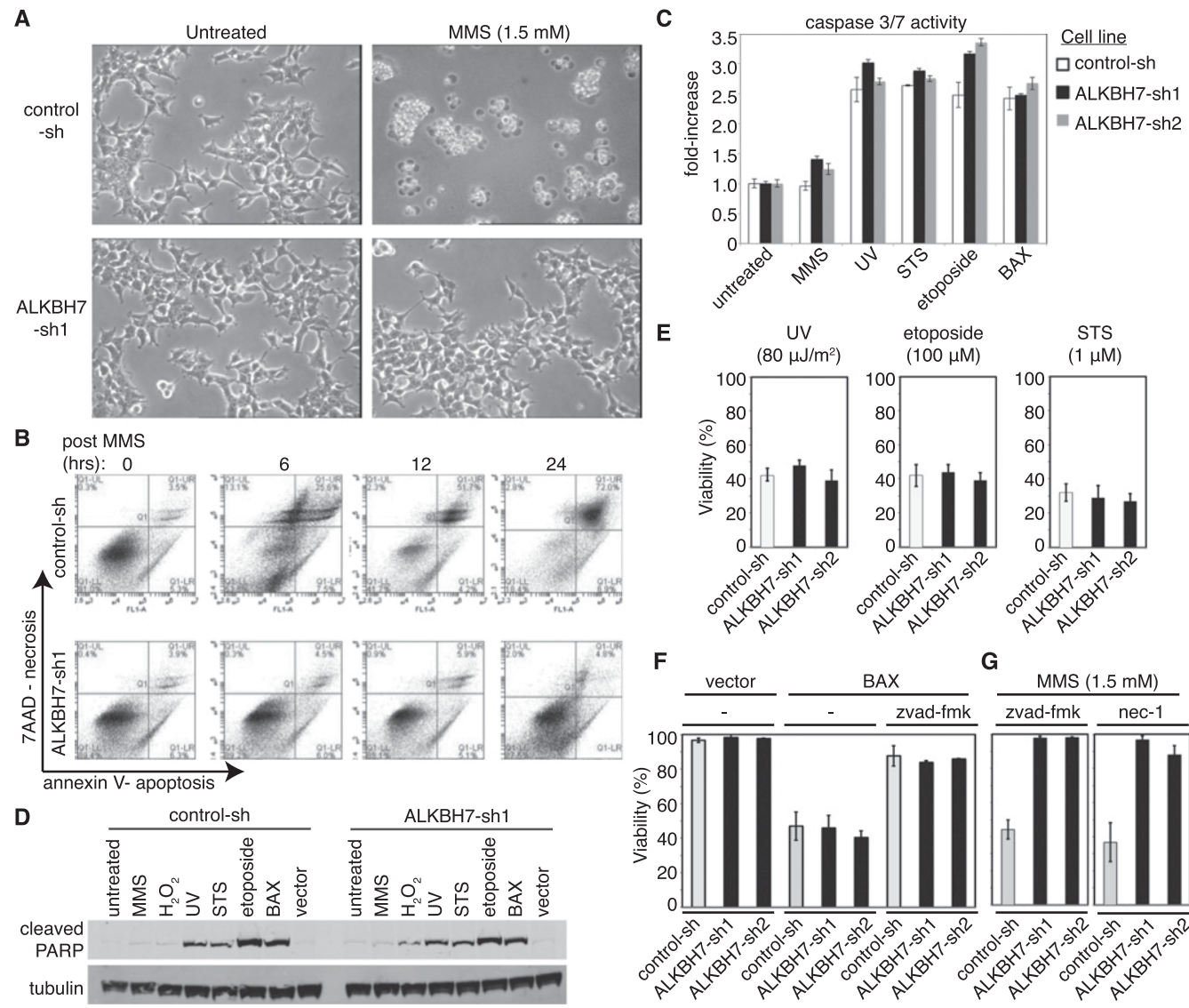

E

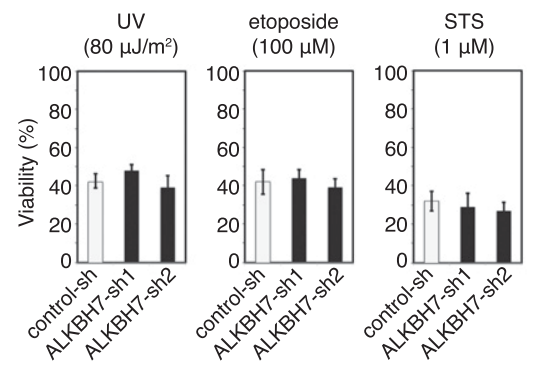

$\mathbf{F}$

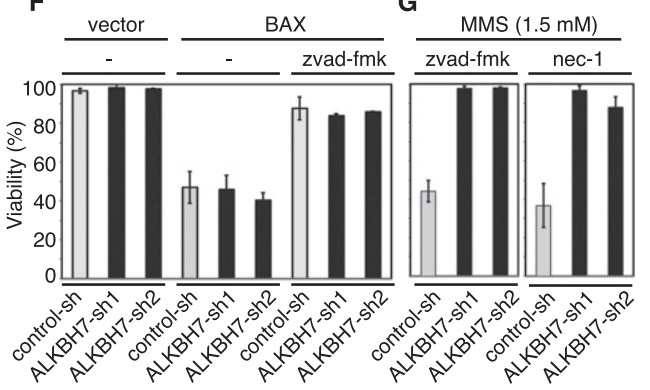

Figure 3. ALKBH7 depletion inhibits necrotic cell death but not apoptosis. (A) Phase-contrast images of control-sh and ALKBH7depleted 293T cells that were left untreated or treated with the indicated concentration of MMS. Images were taken $24 \mathrm{~h}$ after initiation of treatment. $(B)$ Scatter plots of 7AAD positivity for plasma membrane permeabilization (necrosis) and annexin V staining (apoptosis), as measured simultaneously through flow cytometry in single cells at the indicated time points post-MMS treatment. (C) Caspase 3/7 activation in $293 \mathrm{~T}$ cell lines after treatment with the indicated agents. Bars represent the standard deviation of three independent experiments. $(D)$ Immunoblot analysis of cleaved PARP in control-sh and ALKBH7-depleted cell lines after exposure to the indicated agent or transient expression of the proapoptotic protein BAX. $(E-G)$ Viability of control-sh and ALKBH7-depleted cell lines after exposure to the indicated agent or after transient expression of the apoptosis-inducing protein BAX. Cells were treated with MMS (1.5 $\mathrm{mM})$ or $\mathrm{H}_{2} \mathrm{O}_{2}(1 \mathrm{mM})$ for $1 \mathrm{~h}$, while STS $(1 \mu \mathrm{M})$ or etoposide $(100 \mu \mathrm{M})$ were left in the culture medium until analysis. UV irradiation was delivered at $80 \mu \mathrm{J} / \mathrm{m}^{2}$. In some experiments, the caspase inhibitor z-vad-fmk (100 $\left.\mu \mathrm{M}\right)$ or the RIP kinase inhibitor nec-1 (50 $\left.\mu \mathrm{M}\right)$ was added to the medium after transfection or treatment. Bars represent the standard deviation of at least three independent experiments.

be independent of the RIP kinase-dependent necroptotic pathway (Tang et al. 2010; Wang et al. 2012). Indeed, we found that addition of the RIP kinase inhibitor necrostatin1 (nec-1) was unable to prevent necrotic cell death induced by MMS (Fig. 3G). However, nec-1 was able to block programmed necrotic cell death induced by TNF- $\alpha$ in L929 mouse cells, indicating that the nec-1 inhibitor was active (data not shown). Thus, ALKBH7 is required for DNA damage-induced necrosis induced by alkylating or oxidizing agents that is independent of nec-1 inhibition.

\section{ALKBH7 prevents the recovery of cellular bioenergetics after DNA damage-induced PARP hyperactivation}

DNA damage-induced programmed necrosis has been linked to the hyperactivation of the $\mathrm{NAD}^{+}$-consuming enzyme PARP; PARP hyperactivation leads to $\mathrm{NAD}^{+}$ depletion, loss of ATP, and eventual bioenergetic collapse. We therefore tested whether PARP hyperactivation and $\mathrm{NAD}^{+}$depletion are involved in the MMS-induced death of $293 \mathrm{~T}$ cells and whether ALKBH7 plays a role in this process. Upon MMS treatment, we found that PARP was hyperactivated to the same extent in both control and ALKBH7-depleted cells, as indicated by the formation of poly(ADP ribose) (PAR)-modified proteins (Supplemental Fig. S3B). Moreover, we found that both control and ALKBH7-depleted cells suffered a dramatic decrease in both $\mathrm{NAD}^{+}$and ATP starting as early as $30 \mathrm{~min}$ after MMS treatment (Fig. 4A,B), consistent with the hyperactivation of PARP in response to DNA damage. However, in notable contrast to control cells, the ALKBH7depleted cells recovered their $\mathrm{NAD}^{+}$and ATP levels starting $6 \mathrm{~h}$ post-MMS treatment, returning to basal levels by $24 \mathrm{~h}$. Thus, both control and ALKBH7-depleted cells undergo DNA damage-induced PARP hyperactivation 
Fu et al.
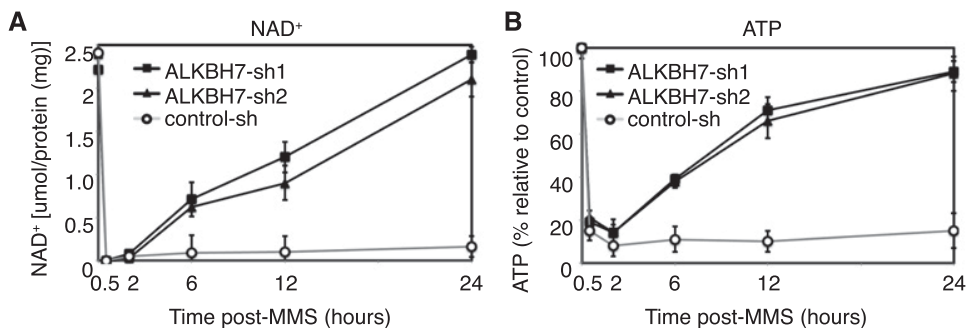

C
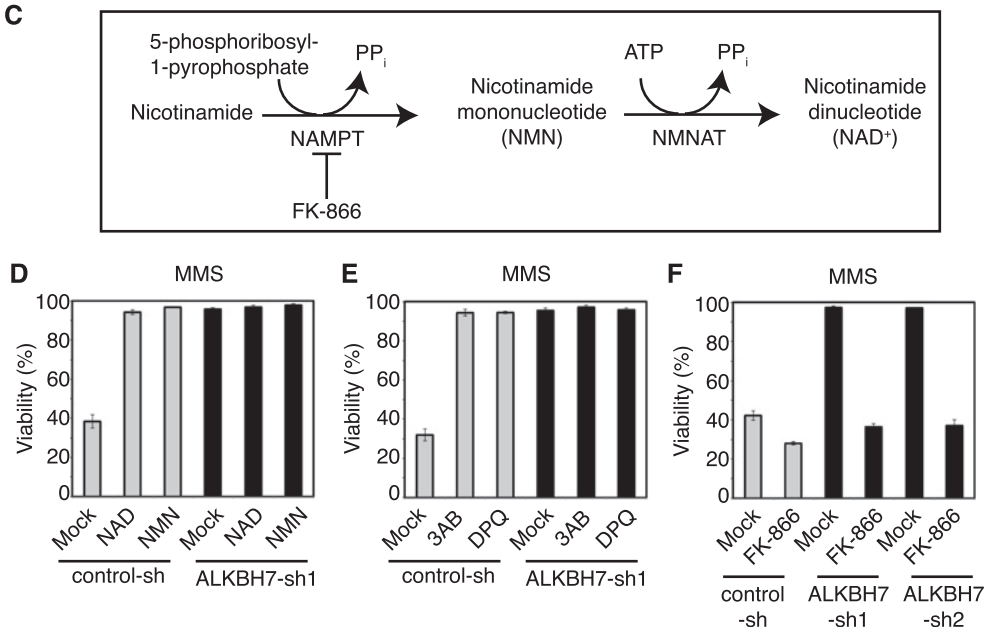

Figure 4. ALKBH7 prevents the recovery of $\mathrm{NAD}^{+}$ and ATP levels after MMS treatment that is necessary for cellular survival after exposure to MMS $1.5 \mathrm{mM}$ for $1 \mathrm{~h}) .(A, B)$ Measurement of $\mathrm{NAD}^{+}$or ATP levels in the indicated 293T human embryonic kidney cell lines after MMS treatment. $(C)$ Enzymes and metabolites of the $\mathrm{NAD}^{+}$salvage pathway. (NAMPT) Nicotinamide phosphoribosyltransferase; (NMNAT) nicotinamide mononucleotide adenylyltransferase; $\left(\mathrm{PP}_{\mathrm{i}}\right)$ inorganic pyrophosphate. $(D)$ Viability of control-sh or ALKBH7depleted cell lines after treatment with MMS, followed by the addition of either mock buffer, NAD ${ }^{+}$ (10 mM), or NMN (10 mM). (E) Viability of control-sh or ALKBH7-depleted cell lines after treatment with MMS in the absence or presence of either of the PARP inhibitors: $3 \mathrm{AB}(2 \mathrm{mM})$ or DPQ $(20 \mu \mathrm{M})$. $(F)$ Viability of control-sh or ALKBH7-depleted cell lines after treatment with MMS, followed by the absence or presence of the NAMPT inhibitor FK-866 (10 nM). Bars for all graphs represent the mean of at least three independent experiments. that leads to massive depletion of total cellular $\mathrm{NAD}^{+}$ and ATP, but ALKBH7-depleted cells regained $\mathrm{NAD}^{+} / \mathrm{ATP}$ homeostasis and maintained cell viability. Our results suggest that ALKBH7 functions to prevent wild-type cells from regaining $\mathrm{NAD}^{+} / \mathrm{ATP}$ homeostasis after acute exposure to genotoxic compounds.

The rapid recovery of $\left[\mathrm{NAD}^{+}\right]$and $[\mathrm{ATP}]$ levels in ALKBH7-depleted cells, which coincides with the maintenance of cell viability, indicates that the recovery of cellular bioenergetic metabolites is a crucial step in preventing the execution of cellular necrosis. The recovery of cellular $\mathrm{NAD}^{+}$could occur through the import of exogenous $\mathrm{NAD}^{+}$, if present at high enough levels; through the $\mathrm{NAD}^{+}$salvage pathway from $\mathrm{NAD}^{+}$precursors (Fig. $4 \mathrm{C}$ ); or both. Indeed, the addition of exogenous $\mathrm{NAD}^{+}$or the $\mathrm{NAD}^{+}$precursor nicotinamide mononucleotide (NMN) to the culture medium suppresses MMS sensitivity in control 293 T cells (Fig. 4D). As expected, ALKBH7-depleted cells were not affected by the addition of $\mathrm{NAD}^{+}$, since they were already MMS-resistant. As a corollary experiment, we tested whether PARP inhibition could suppress MMS sensitivity in control 293 T cells after MMS treatment by preventing the massive decrease in $\left[\mathrm{NAD}^{+}\right]$and $[\mathrm{ATP}]$. We tested the PARP inhibitors 3-aminobenzimide (3AB) and 3,4-dihydro-5[4-(1-piperindinyl)butoxy]-1(2H)-isoquinoline (DPQ) by coincubation during MMS treatment. Similar to $\mathrm{NAD}^{+}$repletion, the blockade of PARP activation completely suppresses MMS-induced cell death, again indicating that $\mathrm{NAD}^{+}$levels are crucial for cell survival after alkylating agent treatment (Fig. 4E).

The recovery of total cellular $\left[\mathrm{NAD}^{+}\right]$in ALKBH7depleted cells suggests that, when present, ALKBH7 prevents $\mathrm{NAD}^{+}$resynthesis after PARP hyperactivation, potentially by inhibiting $\mathrm{NAD}^{+}$-forming pathways that are required to regenerate the $\mathrm{NAD}^{+}$consumed during PARP hyperactivation. To test this idea, we determined whether disruption of $\mathrm{NAD}^{+}$salvage pathways in ALKBH7depleted cells could perturb their MMS-resistant phenotype. For these analyses, we used the inhibitor FK-866, which inhibits the nicotinamide phosphoribosyltransferase (NAMPT) enzyme within the $\mathrm{NAD}^{+}$salvage pathway (Fig. 4C; Yang et al. 2007; Pittelli et al. 2010). Previous studies have shown that FK-866 can dramatically enhance MMS-induced cell death in numerous mammalian cell types (Yang et al. 2007; Goellner et al. 2011). We treated control and ALKBH7-depleted cell lines with MMS, followed by the addition of FK- 866 at a concentration that does not itself result in cell death within the time span of the experiment. As expected for the important role of maintaining $\mathrm{NAD}^{+}$homeostasis, control cells treated with MMS underwent cell death that was further increased by NAMPT inhibition using FK-866 (Fig. 4F). More importantly, we found that the MMS-resistant phenotype exhibited by ALKBH7-depleted cells could be completely suppressed by treatment with FK-866 (Fig. 4F). Thus, inhibition of the $\mathrm{NAD}^{+}$salvage pathway nullifies the MMS-resistant phenotype of ALKBH7depleted cells. Together, these results indicate that ALKBH7 plays a role in suppressing the recovery of cellular bioenergetics and, as a consequence, promotes the onset of cellular necrosis. The recovery of physiological $\mathrm{NAD}^{+}$and ATP levels in ALKBH7-depleted cells indicates that in wild-type cells, the initial loss of total cellular $\mathrm{NAD}^{+}$precedes an ALKBH7-dependent step that prevents recovery of $\mathrm{NAD}^{+}$pools, thus promoting necrotic cell death. 


\section{ALKBH7 plays a key role in mitochondrial dysfunction leading to programmed necrosis}

The regeneration of $\left[\mathrm{NAD}^{+}\right]$and $[\mathrm{ATP}]$ after PARP hyperactivation in ALKBH7-depleted cells indicates that ALKBH7 modulates a step after $\mathrm{NAD}^{+}$depletion that inhibits recovery of cellular bioenergetic status. The opening of the mitochondrial permeability transition (MPT) pore, dissolution of the mitochondria membrane potential $(\Delta \Psi \mathrm{m})$, and formation of ROS are closely associated with programmed necrotic cell death, with each cellular event contributing to the eventual demise of the cell. Since ALKBH7 is required for necrotic cell death after PARP hyperactivation and $\mathrm{NAD}^{+} / \mathrm{ATP}$ depletion, we determined whether ALKBH7 plays a role in the initiation of mitochondrial dysfunction that occurs after severe DNA damage.

To probe for MPT in cells, we assayed mitochondrial retention of calcein-AM, a fluorescent probe that can only exit through an open MPT pore. In addition, we monitored mitochondrial $\Delta \Psi \mathrm{m}$ using two different types of membrane potential indicators: tetramethylrhodamine (TMRE) and JC-1. Following MMS treatment, we found that control $293 \mathrm{~T}$ cells lose mitochondrial calcein-AM staining as early as $6 \mathrm{~h}$ post-treatment (Fig. 5A), indicating that MPT has occurred. Furthermore, we detected an overall decrease in both TMRE staining and JC-1 red fluorescence in MMS-treated cells, denoting the loss of mitochondrial $\Delta \Psi \mathrm{m}$ after MMS treatment (Fig. 5B-E). Finally, MMS treatment in control cells leads to a significant induction of mitochondrial ROS, as measured using MitoSox Red, a mitochondrial targeted form of the superoxide indicator dihydroethidium (Fig. 5F). Previous studies have shown that ROS formation is required for programmed necrotic cell death induced by alkylating agents or death receptor activation (Vandenabeele et al. 2010; Ethier et al. 2012; Vanlangenakker et al. 2012). Indeed, we found that preincubation of control cells with the antioxidant $\mathrm{N}$-acetylcysteine can rescue control cells from necrotic cell death induced by MMS (Supplemental Fig. S4A).

In vivid contrast to control cells, we found that ALKBH7-depleted cells treated with MMS maintained mitochondrial integrity and function, as measured by each of the aforementioned criteria (Fig. 5A-F). ALKBH7depleted cells maintained a closed MPT pore as well as robust $\Delta \Psi \mathrm{m}$ after MMS treatment, as evidenced by the retention of mitochondrial calcein fluorescence along with JC-1 red and TMRE staining (Fig. 5A-E). Consistent with the maintenance of mitochondrial function and homeostasis, ALKBH7-depleted cells did not exhibit any increase in ROS after MMS treatment (Fig. 5F), even though DNA damage and PARP hyperactivation had
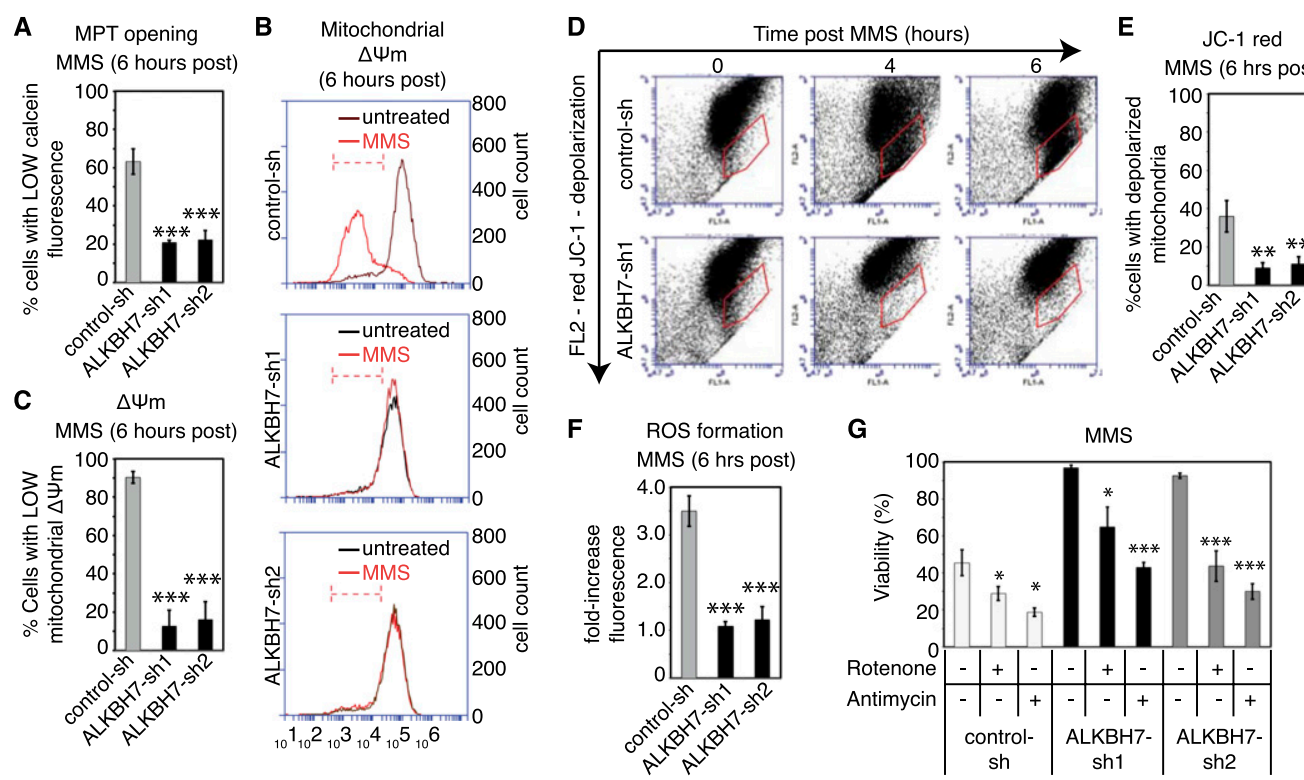

Figure 5. ALKBH7 depletion prevents the MPT, loss of mitochondria membrane potential, and formation of ROS that accompany MMS-induced cell death. For all experiments, cell lines were treated with $1.5 \mathrm{mM}$ MMS for $1 \mathrm{~h}$. (A) Measurement of MPT in control-sh or ALKBH7-depleted cell lines after exposure to MMS. Cells were loaded with calcein-FM, followed by $\mathrm{CoCl}_{2}$ quenching. $(B)$ Representative flow cytometry plot of untreated and MMS-treated cell lines stained with TMRE to monitor mitochondria membrane potential $(\Delta \psi \mathrm{m}) .(C)$ Percentage of cells with low TMRE staining, indicative of reduced mitochondrial $\Delta \psi \mathrm{m}$ after treatment with MMS. Bars represent the mean of three independent experiments. $(D)$ Scatter plots of JC-1 staining for mitochondria membrane potential as measured through JC-1 staining. (E) Quantification of cells with depolarized mitochondria, as measured by the loss of JC-1 red fluorescence, which is indicative of mitochondria membrane depolarization. (F) Quantification of ROS formation. After treatment with MMS, the indicated cell lines were loaded with the mitochondrial superoxide indicator MitoSox Red $(2 \mu \mathrm{M})$, which increases in fluorescence intensity after oxidation. The fold increase in fluorescence signal relative to untreated cells represents the mean of three independent experiments. $(G)$ Viability of control-sh or ALKBH7-depleted cell lines after treatment with MMS in the absence or presence of the ETC inhibitors antimycin $(5 \mu \mathrm{M})$ or rotenone $(25 \mu \mathrm{M})$. Bars for all graphs represent the mean of at least three independent experiments. $\left(^{\star}\right) P<0.05 ;\left(^{\star \star}\right) P<0.01 ;\left(^{\star \star \star}\right) P<0.001$. 
occurred, accompanied by $\left[\mathrm{NAD}^{+}\right]$and [ATP] depletion. The maintenance of mitochondrial function most likely explains the recovery of $\mathrm{NAD}^{+}$and ATP levels in ALKBH7depleted cells after MMS treatment, thus allowing cells to survive and prevent necrotic cell death.

Based on the ALKBH7-dependent loss of mitochondrial homeostasis after MMS treatment, we hypothesize that ALKBH7 inhibits essential mitochondrial functions to induce mitochondrial perturbation and subsequent programmed necrosis. Since the loss of respiration has previously been linked to caspase-independent mitochondrial cell death (Lartigue et al. 2009), we focused on the respiratory electron transport chain (ETC) as a potential mitochondrial function modulated by ALKBH7. Strikingly, we found that chemical inhibition of either complex I or III of the mitochondrial ETC via rotenone or antimycin, respectively, can suppress the MMS-resistant phenotype of ALKBH7-depleted cells (Fig. 5G). Importantly, treatment with rotenone or antimycin in the absence of MMS did not induce cell death within the time span of the experiment (Supplemental Fig. S4B). Moreover, we found that the presence or absence of glucose had no effect on cell survival after MMS treatment (Supplemental Fig. S4C), suggesting that blockade of respiration but not glycolysis plays a role in ALKBH7-dependent necrosis. We conclude that ALKBH7 plays a pivotal role in triggering the cascade of mitochondrial events leading to eventual programmed necrosis by inhibiting key aspects of mitochondrial function, such as respiration.

\section{ALKBH7-mediated necrosis prevents the accumulation of cells with DNA damage}

To evaluate the possible downstream biological effects of programmed necrosis modulated by ALKBH7, we compared alkylation-induced sister chromatid exchange (SCE) in control and ALKBH7-depleted. As expected, we detected a significant increase in the number of SCEs in MNNG-treated versus untreated cells for both the control and ALKBH7-depleted cell line (Fig. 6A; Supplemental Fig. S5). However, both the spontaneous frequency and MNNG-induced frequency of SCEs were significantly higher in ALKBH7-depleted cells versus control cells (Fig. 6). We infer that the induction of programmed necrosis by severe DNA damage may serve as a mechanism to eliminate cells harboring excessive genomic damage, thus preventing the accumulation of cells with chromosomal aberrations. Depletion of ALKBH7 allows these cells to survive even in the presence of recombinogenic and potentially mutagenic DNA damage.

\section{Discussion}

Programmed necrosis induced by excessive DNA damage can be initiated by PARP hyperactivation, leading to $\mathrm{NAD}^{+} / \mathrm{ATP}$ depletion, mitochondrial depolarization, ROS production, and eventual plasma membrane permeability. While many of the cellular aspects of programmed necrosis have been characterized, the factors responsible for initiating and carrying out programmed necrotic cell death are only beginning to be found. Here, we show that a mammalian ALKBH protein, ALKBH7, represents a crucial link in the necrotic cellular cascade induced after PARP hyperactivation by promoting the large-scale loss of mitochondrial function required for programmed necrosis. Loss of ALKBH7 expression facilitates the recovery of cellular metabolites after severe DNA damage, thus allowing cells to remain viable.

All previously characterized mammalian ALKBH dioxygenases have been shown to play a protective role upon exposure to DNA-damaging agents through either the repair of cytotoxic DNA damage (ALKBH2 and ALKBH3) or the modulation of DNA damage survival pathways via tRNA modification (ALKBH8). However, we found that another ALKBH protein, ALKBH7, actually facilitates cell death after exposure to alkylating or oxidizing agents, thus playing a novel prodeath function. These results expand the functions of ALKBH proteins beyond that of nucleic acid repair and modification and uncover a novel role for ALKBH7 in programmed necrosis.

How does ALKBH7 suppress the recovery of biological metabolites to promote necrosis? We propose that ALKBH7 inhibits mitochondrial function after PARP hyperactivation to prevent the regeneration of vital bioenergetic metabolites such as $\mathrm{NAD}^{+}$and ATP (Fig. 7). Based on our results, ALKBH7 is required for the massive loss of mitochondrial homeostasis, which leads to MPT pore opening and the efflux of $\mathrm{NAD}^{+}$into the cytoplasm, allowing
A

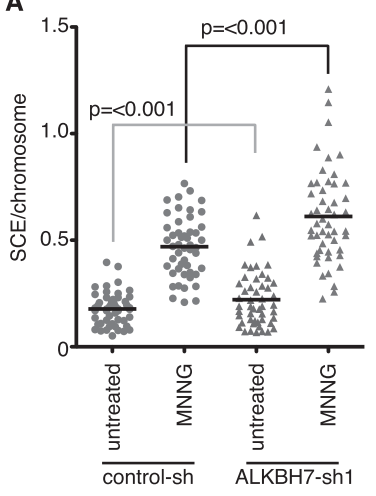

B

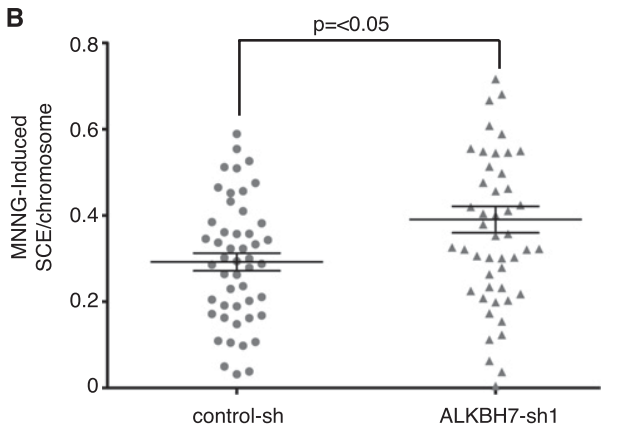

Figure 6. Programmed necrosis inhibits the accumulation of cells with genomic DNA damage. $(A)$ SCEs per chromosome of the indicated cell lines with or without treatment with MNNG $(20 \mu \mathrm{M})$. Scatter plots represent the aggregate of two independent experiments. (B) MNNG-induced frequency of SCE in the indicated cell lines. 


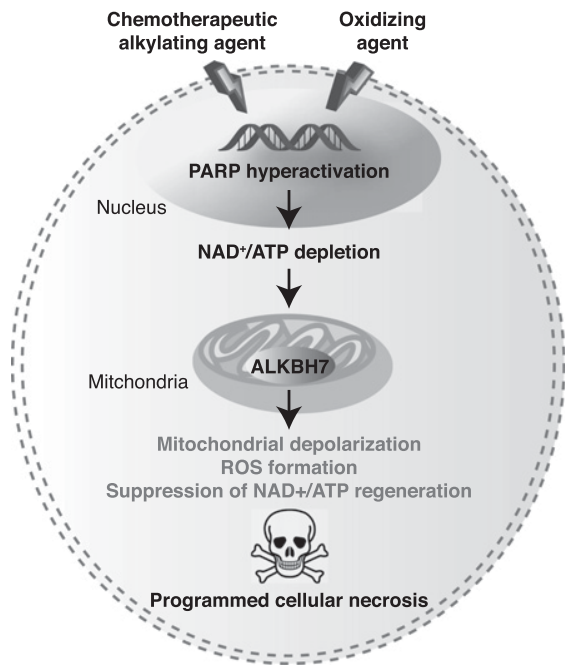

Figure 7. Model for alkylating and oxidizing agent-induced necrotic cell death modulated by ALKBH7. See the Discussion for details.

further consumption by nuclear PARP. NAD ${ }^{+}$is particularly important in mitochondria, since numerous oxidative phosphorylation enzymes require $\mathrm{NAD}^{+}$for function. Moreover, the maintenance of mitochondrial $\left[\mathrm{NAD}^{+}\right]$by the NAD salvage pathway is essential for cellular survival after DNA damage (Yang et al. 2007). Massive $\mathrm{NAD}^{+}$ consumption by PARP, coupled with $\mathrm{NAD}^{+}$efflux, can lead to loss of all energy production and abrogation of the proton gradient as cells try to regenerate $\mathrm{NAD}^{+}$using ATP; this vicious cycle eventually results in mitochondrial dysfunction and formation of toxic ROS. All of these features are observed in cells after MMS treatment and are abrogated in ALKBH7-depleted cells. Since the maintenance of $\mathrm{NAD}^{+}$levels through the $\mathrm{NAD}^{+}$salvage pathway after DNA damage requires ALKBH7, this protein is critical in determining cell fate by preventing $\mathrm{NAD}^{+}$regeneration after cellular stress, thus promoting the loss of mitochondrial function and cell viability.

Recently, the mitochondrial protein phosphatase PGAM5 and p53 were shown to be downstream effectors for the execution of programmed necroptotic cell death by inducing changes in mitochondrial permeability and dynamics (Vaseva et al. 2012; Wang et al. 2012). Like ALKBH7, both PGAM5 and p53 are necessary for programmed necrosis induced by oxidizing agents even though it remains to be seen whether PGAM5 or p53 is required for programmed necrosis induced by alkylating agents. It will be interesting to explore the potential interplay between ALKBH7, p53, and PGAM5 in the execution of mitochondrial dysfunction during necroptotic cell death.

Since many cancer cell types can evade apoptotic cell death through deficiencies in key apoptotic proteins or by inhibition of apoptotic pathways, necrosis presents an attractive target for activation in apoptosis-resistant cancer cells (Kreuzaler and Watson 2012). Indeed, recent studies showed that apoptosis is dispensable for complete tumor regression after alkylating agent chemotherapy because other forms of cell death can be activated, including programmed necrosis (Guerriero et al. 2008). Moreover, necrosis promotes the clearance of apoptosis-deficient tumors by stimulating the innate immune response, a process that is dependent on the necrosis-dependent release of the HMGB1 protein (Guerriero et al. 2011). Interestingly, 293T human cells are highly resistant to some forms of apoptosis induced by viral infection, TNF- $\alpha$, or the anti-Fas antibody due to the expression of SV-40 T antigen and the adenoviral E1b19K and E1b55K oncoproteins, which inhibit p53-dependent and p53-independent apoptosis (Grimm et al. 1996; Fearnhead et al. 1997; Cuconati and White 2002). In contrast to apoptosis, however, ALKBH7dependent necrotic cell death is readily triggered by alkylating or oxidizing agents. These studies suggest that activation of ALKBH7 in apoptosis-resistant cancer cells could serve to enhance the toxic effects of chemotherapeutic alkylating agents in tumors. Our discovery of a role for ALKBH7 in programmed necrosis highlights a potential alternative route to tumor eradication that will be the subject of future investigation. Intriguingly, protein profiling of cancer tissues has revealed that a majority of malignant gliomas and skin cancers exhibit low or negative expression of ALKBH7 (Uhlen et al. 2010).

All previously known substrates of AlkB and ALKBH dioxygenases consist of nucleic acid substrates such as DNA or RNA bases. However, we found that ALKBH7 lacks dioxygenase repair activity on canonical AlkB DNA substrates even though ALKBH7 contains all of the active site motifs and residues found in all known active AlkB dioxygenases. Interestingly, mutation of the putative 2-oxoglutarate-binding site in ALKBH7 that is critical for dioxygenase activity in other AlkB enzymes does not affect its ability to promote necrosis. Based on this result, ALKBH7 may display a novel enzymatic activity that does not require 2-oxoglutarate binding. Nondioxygenase activities for AlkB enzymes have been discovered previously, including tRNA methylation by the ALKBH8 enzyme (Fu et al. 2010; Songe-Moller et al. 2010) and DNA lyase activity by the human ALKBH1 and Schizosaccharomyces pombe Abh1 enzymes (Muller et al. 2010; Korvald et al. 2012). It is also possible that ALKBH7 binds nonenzymatically to protein or nucleic acid substrates to initiate the cascade of mitochondrial events that lead to necrosis. Future studies will be devoted to identifying the targets and binding partners of ALKBH7 that regulate the induction of programmed necrosis.

\section{Materials and methods}

Cell culture, plasmids, and shRNA

293T human embryonic kidney, HeLa S3 cervical carcinoma, and derivative stable cell lines were cultured in Dulbecco's minimal essential medium (Gibco Life Technologies) containing $10 \%$ fetal bovine serum (FBS) and $2 \mathrm{mM} \mathrm{L}$-glutamine. For stable RNAi, lentiviral RNAi constructs (Open Biosystems) expressing a nonsilencing shRNA (RHS4459) or one of two shRNAs targeting the ALKBH7 transcript (TRCN0000072764 or TRCN0000072765) were cotransfected with packaging plasmids (psPAX2 and pMD2.G) 
into 293T cells for lentivirus production. As an additional shRNA set, we used the GIPZ RNAi constructs expressing either scramble nonsilencing shRNA (RHS4346) or shRNA targeting ALKBH7 (RHS4430-98514376). The 293T or HeLa cell lines were subsequently infected with lentivirus in the presence of polybrene, followed by stable clone selection using puromycin.

For colony-forming analysis, cells were seeded into $60-\mathrm{mm}$ plates, allowed to attach for $24 \mathrm{~h}$, and exposed to serum-free medium alone or containing MMS for $1 \mathrm{~h}$, followed by replacement with complete medium containing serum. Surviving colonies were scored 6-10 d later by methylene blue staining. For short-term viability assays, cells were exposed to MMS, MNNG, mechlorethamine, temozolomide, $\mathrm{H}_{2} \mathrm{O}_{2}, t$-buOOH, etoposide, or STS (all from Sigma). MMS, MNNG, $\mathrm{H}_{2} \mathrm{O}_{2}$, and $t$-buOOH were incubated in serum-free medium for $1 \mathrm{~h}$, followed by replacement with complete medium containing serum. Mechlorethamine, temozolomide, etoposide, and STS were left in the medium for the duration of the experiment until analysis. UV irradiation $\left(80 \mathrm{~J} / \mathrm{m}^{2}\right)$ was performed using a UV cross-linker (Stratagene) set at a 254-nm wavelength. Viability for MMS, MNNG, mechlorethamine, temozolomide, $\mathrm{H}_{2} \mathrm{O}_{2}, t$-buOOH, UV, and BAX overexpression was determined using a Coulter counter coupled with trypan blue staining (total number of viable treated cells/total number of viable untreated cells), while viability for etoposide and STS was measured by the WST-1 cell proliferation reagent (Roche) according to the manufacturer's instructions. Additional reagents used (all from Sigma) were FK-866, NAD ${ }^{+}, \mathrm{NMN}, 3$-aminobenzamide, DPQ, z-vad-fmk, nec-1, and 7AAD.

$\mathrm{NAD}^{+}$and ATP levels were measured using a NADH/NAD Quantification kit (Abcam, ab65348) or an ATP Colorimetric/ Fluorometric Assay kit (Abcam, ab83355). MPT pore status was determined via calcein staining/ $\mathrm{CoCl}_{2}$ quenching via the MitoProbe Transition Pore Assay kit (Molecular Probes, Life Technologies). Mitochondrial membrane potential was measured with either the mitochondrial dye JC-1 or TMRE ethyl ester, while mitochondrial superoxide levels were detected using MitoSox Red (all from Molecular Probes, Life Technologies). Cells were analyzed on an Accuri C6 flow cytometer (BD Biosciences). Additional information on siRNA knockdown, mammalian expression constructs, and SCE analysis can be found in the Supplemental Material.

\section{Subcellular predication, localization, and fractionation of $A L K B H 7$}

Subcellular localization predication was performed using three independent online algorithms: SherLoc2 (http://abi.inf.unituebingen.de/Services/SherLoc2), MitoProtII (http://ihg.gsf.de/ ihg/mitoprot.html), and TargetP1.1 (http://www.cbs.dtu.dk/ services/TargetP).

Expression constructs encoding ALKBH7-GFP were transiently transfected into $293 \mathrm{~T}$ cells via calcium phosphate-mediated DNA transfer. For mitochondria colocalization, cells were infected with virus expressing red fluorescent protein targeted to mitochondria (CellLight Mitochondria-RFP, BacMam 2.0, Molecular Probes, Life Technologies). Cells were collected at $48 \mathrm{~h}$ post-transfection for formaldehyde fixation and mounting in ProLong anti-fade reagent with DAPI (Molecular Probes, Life Technologies), followed by microscopy.

Subcellular fractionation of $293 \mathrm{~T}$ cells was performed by differential centrifugation according to Graham (2001).

\section{Protein analysis}

Cellular extract preparation, antibodies, protein purification, and enzymatic activity assays were performed essentially as described (Fu et al. 2010) and are described in the Supplemental Material.

\section{Acknowledgments}

We thank Kyle Atmore and Peter Svensson for initial production of the ALKBH7 knockdown cell lines, Jennifer A. Calvo for manuscript comments, and Arne Klungland for sharing unpublished results. This work was funded by NIH grants R01-CA055042, P30-ES002109, and P30-CA014051. D.F. and J.J.J. are funded by American Cancer Society Post-doctoral Fellowships 116155-PF-08-255-01-GMC and PF-12-060-01-DMC, respectively.

\section{References}

Aas PA, Otterlei M, Falnes PO, Vagbo CB, Skorpen F, Akbari M, Sundheim O, Bjoras M, Slupphaug G, Seeberg E, et al. 2003. Human and bacterial oxidative demethylases repair alkylation damage in both RNA and DNA. Nature 421: 859-863.

Alano CC, Garnier P, Ying W, Higashi Y, Kauppinen TM, Swanson RA. 2010. NAD+ depletion is necessary and sufficient for poly(ADP-ribose) polymerase-1-mediated neuronal death. J Neurosci 30: 2967-2978.

Baritaud M, Boujrad H, Lorenzo HK, Krantic S, Susin SA. 2010. Histone H2AX: The missing link in AIF-mediated caspaseindependent programmed necrosis. Cell Cycle 9: 3166-3173.

Biton S, Ashkenazi A. 2011. NEMO and RIP1 control cell fate in response to extensive DNA damage via TNF- $\alpha$ feedforward signaling. Cell 145: 92-103.

Cipriani G, Rapizzi E, Vannacci A, Rizzuto R, Moroni F, Chiarugi A. 2005. Nuclear poly(ADP-ribose) polymerase-1 rapidly triggers mitochondrial dysfunction. J Biol Chem 280: 17227-17234.

Cuconati A, White E. 2002. Viral homologs of BCL-2: Role of apoptosis in the regulation of virus infection. Genes Dev 16: 2465-2478.

Dango S, Mosammaparast N, Sowa ME, Xiong LJ, Wu F, Park K, Rubin M, Gygi S, Harper JW, Shi Y. 2011. DNA unwinding by ASCC3 helicase is coupled to ALKBH3-dependent DNA alkylation repair and cancer cell proliferation. Mol Cell 44: 373-384.

Du L, Zhang X, Han YY, Burke NA, Kochanek PM, Watkins SC, Graham SH, Carcillo JA, Szabo C, Clark RS. 2003. Intramitochondrial poly(ADP-ribosylation) contributes to NAD+ depletion and cell death induced by oxidative stress. I Biol Chem 278: 18426-18433.

Duncan T, Trewick SC, Koivisto P, Bates PA, Lindahl T, Sedgwick B. 2002. Reversal of DNA alkylation damage by two human dioxygenases. Proc Natl Acad Sci 99: 1666016665.

Eisenberg-Lerner A, Kimchi A. 2007. DAP kinase regulates JNK signaling by binding and activating protein kinase $\mathrm{D}$ under oxidative stress. Cell Death Differ 14: 1908-1915.

Ethier C, Tardif M, Arul L, Poirier GG. 2012. PARP-1 modulation of mTOR signaling in response to a DNA alkylating agent. PLOS ONE 7: e47978.

Falnes PO, Johansen RF, Seeberg E. 2002. AlkB-mediated oxidative demethylation reverses DNA damage in Escherichia coli. Nature 419: 178-182.

Fearnhead HO, McCurrach ME, O'Neill J, Zhang K, Lowe SW, Lazebnik YA. 1997. Oncogene-dependent apoptosis in extracts from drug-resistant cells. Genes Dev 11: 1266-1276.

Feoktistova M, Geserick P, Kellert B, Dimitrova DP, Langlais C, Hupe M, Cain K, MacFarlane M, Hacker G, Leverkus M. 2011. cIAPs block Ripoptosome formation, a RIP1/caspase-8 
containing intracellular cell death complex differentially regulated by cFLIP isoforms. Mol Cell 43: 449-463.

Fu D, Brophy JA, Chan CT, Atmore KA, Begley U, Paules RS, Dedon PC, Begley TJ, Samson LD. 2010. Human AlkB homolog ABH8 Is a tRNA methyltransferase required for wobble uridine modification and DNA damage survival. Mol Cell Biol 30: 2449-2459.

Gerken T, Girard CA, Tung YC, Webby CJ, Saudek V, Hewitson KS, Yeo GS, McDonough MA, Cunliffe S, McNeill LA, et al. 2007. The obesity-associated FTO gene encodes a 2-oxoglutarate-dependent nucleic acid demethylase. Science 318: 1469-1472.

Goellner EM, Grimme B, Brown AR, Lin Y-C, Wang X-H, Sugrue KF, Mitchell L, Trivedi RN, Tang J-b, Sobol RW. 2011. Overcoming temozolomide resistance in glioblastoma via dual inhibition of NAD+ biosynthesis and base excision repair. Cancer Res 71: 2308-2317.

Graham JP. 2001. Isolation of mitochondria from tissues and cells by differential centrifugation. Curr Protoc Cell Biol 3.3.1-3.3.15. doi: 10.1002/0471143030.cb0303s04.

Green DR, Galluzzi L, Kroemer G. 2011. Mitochondria and the autophagy-inflammation-cell death axis in organismal aging. Science 333: 1109-1112.

Grimm S, Stanger BZ, Leder P. 1996. RIP and FADD: Two 'death domain'-containing proteins can induce apoptosis by convergent, but dissociable, pathways. Proc Natl Acad Sci 93: 10923-10927.

Guerriero JL, Ditsworth D, Fan Y, Zhao F, Crawford HC, Zong WX. 2008. Chemotherapy induces tumor clearance independent of apoptosis. Cancer Res 68: 9595-9600.

Guerriero JL, Ditsworth D, Catanzaro JM, Sabino G, Furie MB, Kew RR, Crawford HC, Zong WX. 2011. DNA alkylating therapy induces tumor regression through an HMGB1-mediated activation of innate immunity. J Immunol 186: $3517-$ 3526.

Ha HC, Snyder SH. 1999. Poly(ADP-ribose) polymerase is a mediator of necrotic cell death by ATP depletion. Proc Natl Acad Sci 96: 13978-13982.

Jia G, Yang CG, Yang S, Jian X, Yi C, Zhou Z, He C. 2008. Oxidative demethylation of 3-methylthymine and 3-methyluracil in single-stranded DNA and RNA by mouse and human FTO. FEBS Lett 582: 3313-3319.

Korvald H, Falnes PO, Laerdahl JK, Bjoras M, Alseth I. 2012. The Schizosaccharomyces pombe AlkB homolog Abh1 exhibits AP lyase activity but no demethylase activity. DNA Repair (Amst) 11: 453-462.

Kreuzaler P, Watson CJ. 2012. Killing a cancer: What are the alternatives? Nat Rev Cancer 12: 411-424.

Kroemer G, Jaattela M. 2005. Lysosomes and autophagy in cell death control. Nat Rev Cancer 5: 886-897.

Lartigue L, Kushnareva Y, Seong Y, Lin H, Faustin B, Newmeyer DD. 2009. Caspase-independent mitochondrial cell death results from loss of respiration, not cytotoxic protein release. Mol Biol Cell 20: 4871-4884.

Lee DH, Jin SG, Cai S, Chen Y, Pfeifer GP, O'Connor TR. 2005. Repair of methylation damage in DNA and RNA by mammalian AlkB homologues. J Biol Chem 280: 39448-39459.

Luo X, Kraus WL. 2012. On PAR with PARP: Cellular stress signaling through poly(ADP-ribose) and PARP-1. Genes Dev 26: $417-432$.

Mocarski ES, Upton JW, Kaiser WJ. 2012. Viral infection and the evolution of caspase 8-regulated apoptotic and necrotic death pathways. Nat Rev Immunol 12: 79-88.

Moubarak RS, Yuste VI, Artus C, Bouharrour A, Greer PA, Menissier-de Murcia I, Susin SA. 2007. Sequential activation of poly(ADP-ribose) polymerase 1, calpains, and Bax is essential in apoptosis-inducing factor-mediated programmed necrosis. Mol Cell Biol 27: 4844-4862.

Mourtada-Maarabouni M, Pickard MR, Hedge VL, Farzaneh F, Williams GT. 2009. GAS5, a non-protein-coding RNA, controls apoptosis and is downregulated in breast cancer. Oncogene 28: 195-208.

Muller TA, Meek K, Hausinger RP. 2010. Human AlkB homologue $1(\mathrm{ABH} 1)$ exhibits DNA lyase activity at abasic sites. DNA Repair (Amst) 9: 58-65.

Oka S, Ohno M, Tsuchimoto D, Sakumi K, Furuichi M, Nakabeppu Y. 2008. Two distinct pathways of cell death triggered by oxidative damage to nuclear and mitochondrial DNAs. EMBO I 27: 421-432.

Ougland R, Zhang CM, Liiv A, Johansen RF, Seeberg E, Hou YM, Remme J, Falnes PO. 2004. AlkB restores the biological function of mRNA and tRNA inactivated by chemical methylation. Mol Cell 16: 107-116.

Pagliarini DJ, Calvo SE, Chang B, Sheth SA, Vafai SB, Ong SE, Walford GA, Sugiana C, Boneh A, Chen WK, et al. 2008. A mitochondrial protein compendium elucidates complex I disease biology. Cell 134: 112-123.

Pittelli M, Formentini L, Faraco G, Lapucci A, Rapizzi E, Cialdai F, Romano G, Moneti G, Moroni F, Chiarugi A. 2010. Inhibition of nicotinamide phosphoribosyltransferase: Cellular bioenergetics reveals a mitochondrial insensitive NAD pool. I Biol Chem 285: 34106-34114.

Rhee HW, Zou P, Udeshi ND, Martell JD, Mootha VK, Carr SA, Ting AY. 2013. Proteomic mapping of mitochondria in living cells via spatially restricted enzymatic tagging. Science 339: $1328-1331$.

Ringvoll J, Nordstrand LM, Vagbo CB, Talstad V, Reite K, Aas PA, Lauritzen KH, Liabakk NB, Bjork A, Doughty RW, et al. 2006. Repair deficient mice reveal $\mathrm{mABH} 2$ as the primary oxidative demethylase for repairing $1 \mathrm{meA}$ and $3 \mathrm{meC}$ lesions in DNA. EMBO I 25: 2189-2198.

Sedgwick B, Bates PA, Paik J, Jacobs SC, Lindahl T. 2007. Repair of alkylated DNA: Recent advances. DNA Repair (Amst) 6: 429-442.

Solberg A, Robertson AB, Aronsen JM, Rognmo O, Sjaastad I, Wisloff U, Klungland A. 2013. Deletion of mouse Alkbh7 leads to obesity. J Mol Cell Biol doi 10.1093/jmcb/mjt012.

Songe-Moller L, van den Born E, Leihne V, Vagbo CB, Kristoffersen T, Krokan HE, Kirpekar F, Falnes PO, Klungland A. 2010. Mammalian ALKBH8 possesses tRNA methyltransferase activity required for the biogenesis of multiple wobble uridine modifications implicated in translational decoding. Mol Cell Biol 30: 1814-1827.

Tang J-B, Goellner EM, Wang X-H, Trivedi RN, St Croix CM, Jelezcova E, Svilar D, Brown AR, Sobol RW. 2010. Bioenergetic metabolites regulate base excision repair-dependent cell death in response to DNA damage. Mol Cancer Res 8: 67-79.

Tenev T, Bianchi K, Darding M, Broemer M, Langlais C, Wallberg F, Zachariou A, Lopez J, MacFarlane M, Cain K, et al. 2011. The Ripoptosome, a signaling platform that assembles in response to genotoxic stress and loss of IAPs. Mol Cell 43: 432-448.

Thalhammer A, Bencokova Z, Poole R, Loenarz C, Adam J, O'Flaherty L, Schodel J, Mole D, Giaslakiotis K, Schofield CJ, et al. 2011. Human AlkB homologue 5 is a nuclear 2-oxoglutarate dependent oxygenase and a direct target of hypoxiainducible factor $1 \alpha$ (HIF-1 $\alpha)$. PLOS ONE 6: e16210.

Trewick SC, Henshaw TF, Hausinger RP, Lindahl T, Sedgwick B. 2002. Oxidative demethylation by Escherichia coli AlkB directly reverts DNA base damage. Nature 419: 174-178.

Trivedi RN, Wang X-H, Jelezcova E, Goellner EM, Tang J-B, Sobol RW. 2008. Human methyl purine DNA glycosylase and 
Fu et al.

DNA polymerase $\beta$ expression collectively predict sensitivity to temozolomide. Mol Pharmacol 74: 505-516.

Tsuijkawa K, Koike K, Kitae K, Shinkawa A, Arima H, Suzuki T, Tsuchiya M, Makino Y, Furukawa T, Konishi N, et al. 2007. Expression and sub-cellular localization of human $\mathrm{ABH}$ family molecules. J Cell Mol Med 11: 1105-1116.

Uhlen M, Oksvold P, Fagerberg L, Lundberg E, Jonasson K, Forsberg M, Zwahlen M, Kampf C, Wester K, Hober S, et al. 2010. Towards a knowledge-based Human Protein Atlas. Nat Biotechnol 28: 1248-1250.

Vagbo CB, Svaasand EK, Aas PA, Krokan HE. 2013. Methylation damage to RNA induced in vivo in Escherichia coli is repaired by endogenous $\mathrm{AlkB}$ as part of the adaptive response. DNA Repair (Amst) 12: 188-195.

Vandenabeele P, Galluzzi L, Vanden Berghe T, Kroemer G. 2010. Molecular mechanisms of necroptosis: An ordered cellular explosion. Nat Rev Mol Cell Biol 11: 700-714.

Vanlangenakker N, Vanden Berghe T, Vandenabeele P. 2012. Many stimuli pull the necrotic trigger, an overview. Cell Death Differ 19: 75-86.

Vaseva AV, Marchenko ND, Ji K, Tsirka SE, Holzmann S, Moll UM. 2012. p53 opens the mitochondrial permeability transition pore to trigger necrosis. Cell 149: 1536-1548.

Wang Z, Jiang H, Chen S, Du F, Wang X. 2012. The mitochondrial phosphatase PGAM5 functions at the convergence point of multiple necrotic death pathways. Cell 148: 228243.

Westbye MP, Feyzi E, Aas PA, Vagbo CB, Talstad VA, Kavli B, Hagen L, Sundheim O, Akbari M, Liabakk NB, et al. 2008. Human AlkB homolog 1 is a mitochondrial protein that demethylates 3-methylcytosine in DNA and RNA. I Biol Chem 283: 25046-25056.

Yang H, Yang T, Baur JA, Perez E, Matsui T, Carmona JJ, Lamming DW, Souza-Pinto NC, Bohr VA, Rosenzweig A, et al. 2007. Nutrient-sensitive mitochondrial NAD+ levels dictate cell survival. Cell 130: 1095-1107.

Yang Y, Xia F, Hermance N, Mabb A, Simonson S, Morrissey S, Gandhi P, Munson M, Miyamoto S, Kelliher MA. 2011. A cytosolic ATM/NEMO/RIP1 complex recruits TAK1 to mediate the NF- $\mathrm{kB}$ and $\mathrm{p} 38$ mitogen-activated protein kinase (MAPK)/MAPK-activated protein 2 responses to DNA damage. Mol Cell Biol 31: 2774-2786.

Yi C, He C. 2013. DNA repair by reversal of DNA damage. Cold Spring Harb Perspect Biol 5: a012575.

Yu SW, Wang H, Poitras MF, Coombs C, Bowers WJ, Federoff HJ, Poirier GG, Dawson TM, Dawson VL. 2002. Mediation of poly(ADP-ribose) polymerase-1-dependent cell death by apoptosis-inducing factor. Science 297: 259-263.

Zalckvar E, Yosef N, Reef S, Ber Y, Rubinstein AD, Mor I, Sharan R, Ruppin E, Kimchi A. 2010. A systems level strategy for analyzing the cell death network: Implication in exploring the apoptosis/autophagy connection. Cell Death Differ 17: 1244-1253.

Zheng G, Dahl JA, Niu Y, Fedorcsak P, Huang CM, Li CJ, Vagbo $\mathrm{CB}$, Shi Y, Wang WL, Song SH, et al. 2013. ALKBH5 is a mammalian RNA demethylase that impacts RNA metabolism and mouse fertility. Mol Cell 49: 18-29.

Zong WX, Thompson CB. 2006. Necrotic death as a cell fate. Genes Dev 20: 1-15.

Zong WX, Ditsworth D, Bauer DE, Wang ZQ, Thompson CB. 2004. Alkylating DNA damage stimulates a regulated form of necrotic cell death. Genes Dev 18: 1272-1282. 


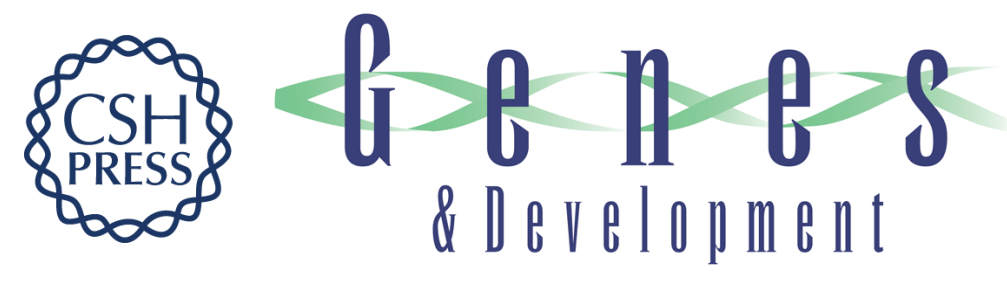

\title{
Human ALKBH7 is required for alkylation and oxidation-induced programmed necrosis
}

\author{
Dragony Fu, Jennifer J. Jordan and Leona D. Samson
}

Genes Dev. 2013, 27: originally published online May 10, 2013

Access the most recent version at doi:10.1101/gad.215533.113

\section{Supplemental http://genesdev.cshlp.org/content/suppl/2013/05/02/gad.215533.113.DC1 Material}

References This article cites 62 articles, 29 of which can be accessed free at: http://genesdev.cshlp.org/content/27/10/1089.full.html\#ref-list-1

\section{License}

Email Alerting

Receive free email alerts when new articles cite this article - sign up in the box at the top Service 